\title{
AGGREGATE ANALYSTS' REVISIONS AND MARKET REACTION
}

\author{
Xinmei Xie, California State University-Dominguez Hills, Carson, California, USA
} Lilin Liu, California State University-Dominguez Hills, Carson, California, USA

dx.doi.org/10.18374/JIFE-13-3.9

\begin{abstract}
Several studies have explored the role of accounting earnings in the capital market at the aggregate level following Kothari et al (2006). However, it is unclear whether accounting earnings are informative as to the market price variations at the aggregate level. In this study, we use aggregate analysts' revisions of earnings forecasts as a proxy for aggregate earnings surprises and explore the relation between market returns and the beliefs of an important user group (analysts) as to future earnings. We find that (1) the direction of analysts' revisions is predictable to some extent with market returns but the magnitude of revisions is not; (2) aggregate analysts' revisions are significantly positively correlated with contemporaneous market returns; (3) there is a weak and negative predictive relation between aggregate analysts' revisions and future market returns. This study not only sheds light on the role of accounting earnings in the capital market but also improves our understanding of financial analysts' role in the stock market.
\end{abstract}

Keywords: Analysts' Revisions, Market Reaction, Aggregate Market Return, Earnings Forecasts. 